\title{
Preschool Children's Speech Pedagogical Sound Culture Correction
}

\author{
Valentyna Ye. Borova,"\#, Liubov V. Artemova ${ }^{2, \#}$, Nataliia I. Melnyk ${ }^{3, \#, *}$, Valentuna Ye. \\ Benera, $^{4, \#}$ and Nataliia V. Malinovska, ${ }^{5, \#}$
}

${ }^{1}$ Department of Elementary and Preschool Education, Academician Stepan Demianchuk International University of Economics and Humanities, Rivne, Ukraine

${ }^{2}$ Department of Preschool Pedagogy and Psychology, Oleksandr Dovzhenko Hlukhiv National Pedagogical University, Glukhiv, Ukraine

${ }^{3}$ Department of Foreign Philology, National Aviation University, Kyiv, Ukraine

${ }^{4}$ Department of Theory and Methods of Preschool and Primary Education, Taras Shevchenko Regional Humanitarian-Pedagogical Academy of Kremenets, Kremenets, Ukraine

${ }^{5}$ Department of Pedagogy and Psychology (Preschool and Correctional) named after Professor T.I. Ponimanska, Rivne State University of the Humanities, Rivne, Ukraine

\begin{abstract}
Objective: The article aims to reveal the features of correction of the sound culture of the preschool-age children's speech, the effectiveness of which has been tested experimentally.

Background: The sound culture of speech is a multicomponent formation, which covers the phonetic correctness of speech; general language skills and orthoepic correctness of speech. Pedagogical correction of the sound culture of speech is focused on the correct the errors caused by a violation of the sound articulation, sound pronunciation, orthoepic norms of pronunciation, voice strength, etc.

Method: In the study, the author's method of pedagogical correction of the sound culture of children's speech was used. Also, it was used comparative analysis and method of successive analysis of adjustment variants of the speech sound culture.

Results: An individual model of pedagogical correction of the sound culture of the child's speech was developed. Training to deepen knowledge, improvement of abilities, and skills of teachers were held. The exercises in sound pronunciation and intonational speech expressiveness were developed.

Conclusion: Positive dynamics of developmental levels of the sound culture of children's speech, which has been confirmed by the results of quantitative and qualitative analysis, confirms the effectiveness of the experimental methods of pedagogical correction of the sound culture of speech.
\end{abstract}

Keywords: Inclusive education, norms of pronunciation, phonetic correctness, phonemes, voice strength.

\section{INTRODUCTION}

Pedagogical correction of the sound culture of speech is focused on the teacher's impact on children to correct the errors caused by a violation of the sound articulation, sound pronunciation, speech breathing, phonemic hearing, orthoepic norms of pronunciation, voice strength, speech tempo and intonation means of expression [1, 2]. It is important to differentiate this definition from the concept of "correction", which is used by specialists of inclusive education. This article is relevant, as an integral part of human speech culture is the sound culture of speech. This is a multicomponent formation, which covers the phonetic correctness of speech (perception and discrimination of phonemes by ear, articulation and pronunciation of

*Address correspondence to this author at the National Aviation University, Kyiv, Ukraine; Tel: +380362653085; E-mail: nata-melnyk@uohk.com.cn

\#These authors are equally contributed. sounds); general language skills (breathing, diction, tempo, the rhythm of speech, voice power and emphasis) and orthoepic correctness of speech (compliance with normative literary pronunciation) [3, 4]. "Sound culture of speech" is the concept used in preschool education, in particular, in the methodology of the preschool children's speech development [5].

Experts in the field of preschool education, pay considerable attention to the problem of individual's speech formation, in particular, they explore the mechanisms of speech realization [6,7], individual characteristics of speech development $[8,9]$. Scientists are discovering methodology for the development of children's speech activity as an important way of communication [10, 11], and others. At the same time, the problem of pedagogical correction of the sound culture of the preschool children's speech has not been the subject of any research. So, it is very necessary to investigate the following matters: 
1. Is the technology of pedagogical correction of sound pronunciation by senior preschool-age children effective in the teaching of the sound culture of the speech?

2. What methods of pedagogical correction of sound culture are effective?

3. Does pedagogical correction of the sound culture of speech influence the qualitative and quantitative indicators of its development by the preschool-age children?

Purpose of research is to reveal the features of the methodology of correction the sound culture of the preschool-age children's speech and to test its effectiveness experimentally. The main objectives of the study are to study the developmental level of the sound culture of preschool children's speech and to develop a unique model of pedagogical correction of the sound pronunciation shortcomings.

\section{MATERIALS AND METHODS}

\section{Study Subject}

Subjects of the study were children of the preschool age from 4 years 5 months to 6 years studying at the urban and rural preschool educational institutions located in the city of Rivne and Rivne region, the town of Kremenets and Ternopil region, city of Lutsk and Volyn region, city of Mykolayiv and Mykolayiv region, city of Zhytomyr and Zhytomyr region. In total, 564 children have been involved in the experiment, 280 of which were the experimental group and 284 - control group. The experimental group implemented the author's method of pedagogical correction of the sound culture of children's speech, the introduction of which should affect the growth of qualitative and quantitative characteristics of the sound culture of speech. The introduction of experimental methods of correction of the sound culture of speech has been implemented in four stages: organizational, executive, reproductive \& artistic, creative \& artistic.

\section{Study Design}

The goal of the first stage, called "Organizational", was studying of the developmental level of sound culture of preschool children's speech, in particular, the features of their sound pronunciation as the basis of speech culture. A unique model of pedagogical correction of the sound pronunciation shortcomings, speech tempo improvement and intonational expressiveness had been developed. Simple shortcomings of children's sound pronunciation had been determined, which successfully were corrected by the teacher working with children of the mentioned group, as well as speech defects, which were the subject of activity of the speech therapist. Masterclasses, training with the purpose of deepening of knowledge, improvement of abilities and skills of teachers employed at the preschool educational institutions majoring in the designated problem were held.

The goal of the second stage, called "Executive" was the formation by children having shortcomings of the sound pronunciation of correct articulation, speech breathing, phonemic hearing and pronunciation of speech sounds, fixing their pronunciation in syllables, words and sentences. To achieve this goal, an individual model of pedagogical correction of the sound culture of the child's speech was developed. In the process of activity, some corrections were introduced due to the peculiarities of mastering the correct pronunciation of sounds by the child, level of general speech development, memory characteristics, perception, attention, desire for a positive result achievement and level of awareness of the own speech shortcomings. Systematic monitoring of achievements of each child in correct sound mastering was carried out.

The goal of the third stage, called "Reproductive and creative" was a correction of the sound culture of the children's speech. Children's activation of speech activity and communication were determined, exercises in the sound pronunciation and intonational speech expressiveness were developed. The outlined goal has been achieved by the involvement of children in verbal didactic, role-playing games, dramatization games, the study of folksy proverbs, poems, telling tales, communication with adults and children.

The goal of the fourth stage, called "Creative" was to consolidate children's knowledge, improve skills and sound culture of speech during independent play and speech activity. In order to achieve the goal, the participation of children in theatrical and game activities, dramatization games and high-days held in the preschool education institution has been organized; speech activity of the group's passive children has been activated.

\section{Ethical Clearance}

All procedures performed in studies involving human participants were in accordance with the ethical 
standards of the institutional and national research committee and with the 1964 Helsinki declaration and its later amendments or comparable ethical standards. A study was approved by the Central Ethics Committee of the Ministry of Health of Ukraine, March 18, 2020, No. 1594-IA. Informed consent was obtained from all individual participants included in the study.

\section{RESULTS}

The study took place in the 2019-2020 academic years the urban and rural preschool educational institutions located in the city of Rivne and Rivne region, the town of Kremenets and Ternopil region, city of Lutsk and Volyn region, city of Mykolayiv and Mykolayiv region, city of Zhytomyr and Zhytomyr region. Specially calculated structure of the selection and its size (564 respondents balanced by gender and age) (Table 1).

After completion of the experiment, the positive dynamics of the level of sound culture of speech of the children's experimental group has been observed, while in the control group, these changes were less

Table 1: Characteristics of Age Groups

\begin{tabular}{|c|c|c|c|}
\hline Age & Number of women & Number of men & Total number of persons \\
\hline 4 years 5 months & 22 & 18 & 40 \\
\hline 5 years & 63 & 47 & 110 \\
\hline 5 years 5 months & 97 & 82 & 179 \\
\hline 6 years & 122 & 113 & 235 \\
\hline
\end{tabular}

Table 2: Dynamics of Formation Levels of the Sound Culture of Children's Speech

\begin{tabular}{|c|c|c|c|c|c|c|c|c|}
\hline \multirow{3}{*}{ Levels } & \multicolumn{4}{|c|}{ Control group } & \multicolumn{4}{|c|}{ Experimental group } \\
\hline & \multicolumn{2}{|c|}{$\begin{array}{l}\text { Before the experiment } \\
n=284\end{array}$} & \multicolumn{2}{|c|}{$\begin{array}{l}\begin{array}{c}\text { After the experiment } \\
n=284\end{array}\end{array}$} & \multicolumn{2}{|c|}{$\begin{array}{l}\text { Before the experiment } \\
\qquad n=280\end{array}$} & \multicolumn{2}{|c|}{$\begin{array}{l}\text { After the experimen } \\
\qquad \mathrm{n}=\mathbf{2 8 0}\end{array}$} \\
\hline & f & $\%$ & $f$ & $\%$ & $\mathbf{f}$ & $\%$ & $f$ & $\%$ \\
\hline elementary & 68 & 23.94 & 59 & 20.77 & 70 & 25 & 9 & 3.21 \\
\hline reproductive & 162 & 57.04 & 144 & 50.70 & 160 & 57.14 & 62 & 22.14 \\
\hline normative & 45 & 15.84 & 67 & 23.59 & 57 & 13.22 & 16.4 & 58.57 \\
\hline creative & 9 & 3.18 & 14 & 4.94 & 13 & 4.64 & 45 & 16.08 \\
\hline
\end{tabular}

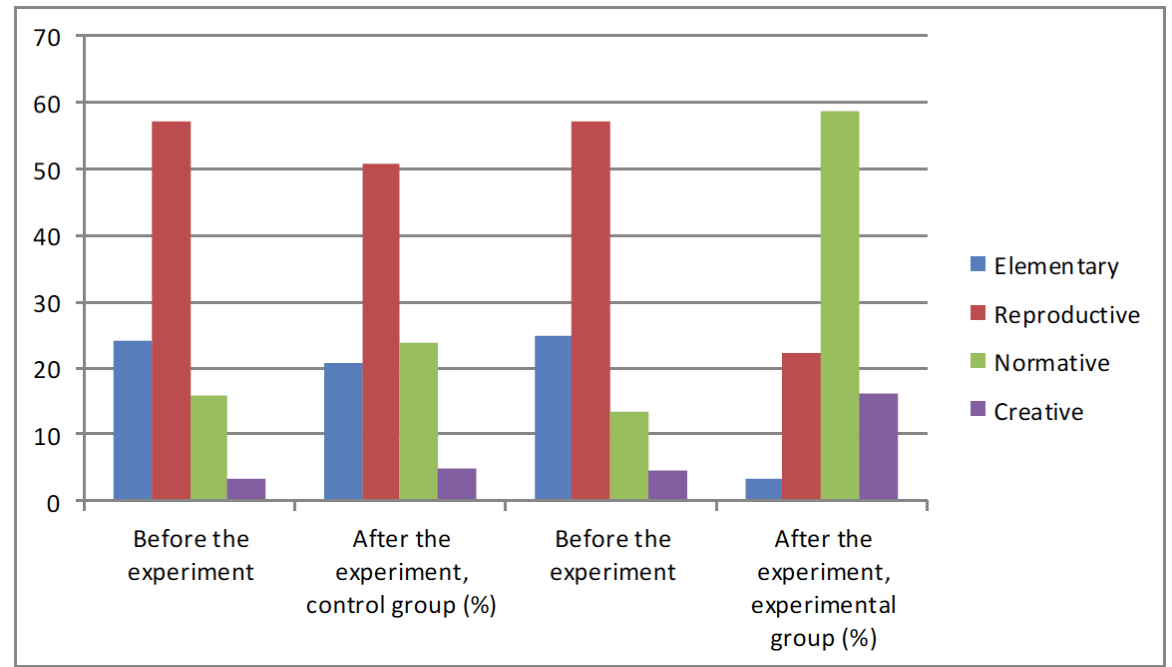

Figure 1: Distribution of respondents by levels of development of a sound culture of speech.

Source: authors' own research. 
significant. The results of the control testing (Table 2, Figure 1) showed that by children of the experimental group, where the author's method of correcting the shortcomings of the sound culture of speech was introduced, statistically significant shifts towards the growth of the level of the sound culture of speech as a whole were observed.

Comparative analysis of the developmental levels of speech sound culture of children belonging to experimental and control groups suggests the effectiveness of the pedagogical impact of adjustments to the mastery of children a certain phenomenon. It is necessary to correlate the methods and techniques of training and education with the child's age characteristics to achieve the pedagogical goal. In the process of activity, the teacher of preschool education of the experimental group is more professional than the teacher of the control group because he took into account the actual need of the preschooler in games and communication, which are vital in such circumstances.

Using the game, the adult achieved a didactic goal, met the child's needs and contributed to the acquisition of new knowledge and skills. The teacher needs to make timely changes in the method of correction of the child's speech sound culture, depending on his individual achievements and potential. By the method of successive analysis of adjustment variants of the speech sound culture, we can define an individual method of work with a specific child. It is important to ensure an interested and conscious attitude to its performance of tasks offered by the teacher. To promote such a situation, the expressiveness and imagery of the teacher's speech at the preschool educational institution will be a role model for preschoolers.

\section{DISCUSSION}

While problem research we used methods of analysis and synthesis of linguistic, psychological, psycholinguistic and pedagogical sources the current state of pedagogical correction of the sound culture of preschool-age children's speech was studied and generalized. The analysis of their speech, fixation of the sound communication errors of children, shortcomings of speech intonational expressiveness, comparison and classification for determining the effectiveness of teachers' activity in this sphere were made. Also, it was used a pedagogical experiment with qualitative and quantitative analysis of the results obtained, in particular, the statistical criterion developed by Kolmogorov-Smirnov $[12,13]$.

In the first stage, conditions for effective pedagogical activity have been created: selected didactic material, visual and audio support of classes, plan of interaction with the speech therapist and parents has been developed. To achieve the goal of the second stage, further steps in joint speech child's activity with the preschool educational institution teacher, parents, and speech therapist were defined. To achieve the goal of the third stage, such conditions of activity have been provided: word games have been selected as the natural means of the preschool children's interpersonal communication organizing, knowledge of children about the professional activities of adults has been expanded and clarified by observing it, recommended fiction works have been read, attributes for playing activities have been replenished, the amount of time allotted for children's independent playing activities has been increased. Conditions for the realization of goals of the "Creative stage" have been provided, such as

- $\quad$ scenarios of holidays for children have been developed,

- $\quad$ children have been acquainted with fairy tales,

stories and cartoons available for dramatization,

performances of puppet and drama theatres have been visited.

Outstanding psychologist D. Yelkonin argued that the sound form of speech becomes the subject of early child's knowledge and activity [14]. The scientist called the awareness of sound side of speech as the main qualitative new formation of mental development of the five-year-old children. This is important to consider because an adequate assessment of the child's skills and abilities is the basis for assimilation of speech culture and its correction $[15,16]$.

D. Yelkonin was one of the first who put forward the idea that a preschool-age child reaches the level of speech mastery when it becomes not the only approach of communication and knowledge, but also the subject of study $[17,18]$. Disadvantages of speech prevent the preschool-age child from communicating comfortably with peers, other children or adults. Often such child hesitates to respond to the suggestions of the teacher and peers, to address questions and comments to others, to recite poems, to tell fairy tales, 
etc. Outlined disadvantages negatively affect the successful speech mastering. Speech defects can injure a child's psyche.

\section{CONCLUSIONS}

Analysis of the results gained while research indicates the lack of implementation of role-playing games while correction of the sound culture of the preschool children's speech. To study their role in the outlined activities will be directed to our further investigations. Reliability of data obtained at the formation stage of the experiment was verified by the Kolmogorov-Smirnov statistical criterion. Positive dynamics of developmental levels of the sound culture of children's speech, which has been confirmed by the results of quantitative and qualitative analysis, confirms the effectiveness of the experimental methods of pedagogical correction of the sound culture of speech. It provided timely correction of articulation and pronunciation of sounds, development of speech breathing and phonemic hearing, improvement of diction, speech tempo and orthoepic speech correctness.

At all stages, the subject has been provided, mainly by the subjective interaction with children. It has contributed to the increase in the child's activity, provided emotional comfort and intensified communication.

\section{ACKNOWLEDGEMENT}

None.

\section{REFERENCES}

[1] Borova VY. Optimization of correction of the children's sound culture of speech. In: Preschool education within the country and over the world: historical experience, status and prospects: Materials of the international scientific-practical conference. Penza: Educational \& Publishing Center Sotsiosfera 2012.

[2] Lotfi Y, Moossavi A, Afshari PJ, Bakhshi E, Sadjedi $H$. Spectro-temporal modulation detection and its relation to speech perception in children with auditory processing disorder. International Journal of Pediatric Otorhinolaryngology 2020; 131: article number 109860. https://doi.org/10.1016/j.ijporl.2020.109860
[3] Zalevskaya AA. Introduction to psycholinguistics. Moscow: Russian State University of Humanities 2007.

[4] Shukla B, Rao BS, Saxena U, Verma H. Measurement of speech in noise abilities in laboratory and real-world noise. Indian Journal of Otology 2018; 24(2): 109-113. https://doi.org/10.4103/indianjotol.INDIANJOTOL 13417

[5] Ushakova TN. Speech: Sources and principles of development. Moscow: PERSZ, 2004.

[6] Zeitlin SN. Language and child: Linguistics of children's speech. Moscow: Humanitarian publishing center VLADOS 2000.

[7] Hunter C, Pisoni D. Early language experience and underspecified phonological representations. Applied Psycholinguistics 2017; 38(6): 1325-1329. https://doi.org/10.1017/S0142716417000285

[8] Simard D, Labelle M, Bergeron A. Measuring metasyntactic abilities: On a classification of metasyntactic tasks. Journal of Psycholinguistic Research 2017; 46(2): 433-456. https://doi.org/10.1007/s10936-016-9445-z

[9] Arushanova AG. Speech and verbal communication of children: development of dialogical communication: Methodological guide for teachers of kindergarten for work with children of 3-7 years old. Moscow: Mozaika-Sintez 2008

[10] Bohush AM. Speech development of children from birth to 7 years old. Kyiv: Slovo 2004.

[11] Ushakova OS. Development of preschoolers' speech Moscow: Publishing House of Psychotherapy Institute 2001.

[12] Yathiraj A, Vanaja CS. Age-related changes in auditory processes in children aged 6 to 10 years. International Journal of Pediatric Otorhinolaryngology 2015; 79(8): 1224 1234.

https://doi.org/10.1016/j.ijporl.2015.05.018

[13] Loewenberg BD, Forzani FM. The work of teaching and the challenge for teacher education. Journal of Teacher Education 2009; 60(5): 497-511. https://doi.org/10.1177/0022487109348479

[14] Yelkonin DB. Child psychology: Study guide for students of the higher educational institutions. Moscow: Publishing Center "Akademiya" 2007.

[15] Lickona T. Eleven principles of effective character education. Journal of Moral Education 2017; 25(1) https://doi.org/10.1080/0305724960250110

[16] Kim JN, Grunig JE. Problem-solving and communicative action: a situational theory of problem-solving. Journal of Communication 2011; 61(1): 120-149. https://doi.org/10.1111/j.1460-2466.2010.01529.x

[17] Berger CM, Crossley SA, Kyle K. Using novel word context measures to predict human ratings of lexical proficiency. Educational Technology and Society 2017; 20(2): 201-212.

[18] Bell KE, Limber JE. Reading skills, textbook marking, and course performance. Literacy Research and Instruction 2010; 49: 56-67.

https://doi.org/10.1080/19388070802695879 